\title{
The relationship between frailty, nutritional status, co-morbidity, CT-body composition and systemic inflammation in patients with COVID-19
}

Josh McGovern ${ }^{1 *}$, Yassir Al-Azzawi ${ }^{1}$, Olivia Kemp², Peter Moffitt ${ }^{2}$, Conor Richards², Ross D. Dolan ${ }^{2}$, Barry J. Laird ${ }^{3}$, Donald C. McMillan ${ }^{1}$ and Donogh Maguire ${ }^{2}$

\begin{abstract}
Background: Frailty, determined by the Canadian Study of Health and Aging-Clinical Frailty Scale (CFS), is strongly associated with clinical outcomes including mortality in patients with COVID-19. However, the relationship between frailty and other recognised prognostic factors including age, nutritional status, obesity, sarcopenia and systemic inflammation is poorly understood. Therefore, the aim of this study was to examine the relationship between frailty and other prognostic domains, in patients admitted with COVID-19.
\end{abstract}

Methods: Patients who presented to our institutions between 1st April 2020-6th July 2020 with confirmed COVID19 were assessed for inclusion. Data collected included general demographic details, clinicopathological variables, CFS admission assessment, Malnutrition Universal Screening Tool (MUST), CT-BC measurements and markers of systemic inflammation.

Results: 106 patients met the study inclusion criteria. The majority of patients were aged $\geq 70$ years (67\%), male $(53 \%)$ and frail (scoring $>3$ on the CFS, 72\%). The majority of patients were not malnourished (MUST 0, 58\%), had $\geq 1$ co-morbidity (87\%), were sarcopenic (low SMI, 80\%) and had systemic inflammation (mGPS $\geq 1,81 \%, N L R>5,55 \%$ ). On multivariate binary logistics regression analysis, age $(p<0.01)$, COPD $(p<0.05)$ and NLR $(p<0.05)$ remained independently associated with frailty. On univariate binary logistics regression, NLR $(p<0.05)$ was significantly associated with 30-day mortality.

Conclusion: Frailty was independently associated with age, co-morbidity, and systemic inflammation. The basis of the relationship between frailty and clinical outcomes in COVID-19 requires further study.

Trial registration Registered with clinicaltrials.gov (NCT04484545)

Keywords: Frailty, Elderly, COVID-19, Body composition

*Correspondence: Josh.McGovern@glasgow.ac.uk

${ }^{1}$ Academic Unit of Surgery, University of Glasgow, Level 2, New Lister Building, Glasgow G31 2ER, UK

Full list of author information is available at the end of the article

\section{Introduction}

The World Health Organization (WHO) declared the outbreak of novel coronavirus 19 (COVID-19) a global pandemic on the 11th of March 2020 [1]. During the first wave of the pandemic, the Canadian Study of Health and Aging-Clinical Frailty Scale (CFS) [2] was utilised to aid original author(s) and the source, provide a link to the Creative Commons licence, and indicate if changes were made. The images or other third party material in this article are included in the article's Creative Commons licence, unless indicated otherwise in a credit line to the material. If material is not included in the article's Creative Commons licence and your intended use is not permitted by statutory regulation or exceeds the permitted use, you will need to obtain permission directly from the copyright holder. To view a copy of this licence, visit http://creativecommons.org/licenses/by/4.0/. The Creative Commons Public Domain Dedication waiver (http://creativeco mmons.org/publicdomain/zero/1.0/) applies to the data made available in this article, unless otherwise stated in a credit line to the data. 
decisions on treatment escalation and ceiling of care for patients admitted with COVID-19 [3].

The CFS is a clinical judgement-based frailty tool that evaluates specific domains including comorbidity, function, and cognition [2]. Recent systematic reviews have shown that frailty, determined by the CFS, is associated with clinical outcomes in patients with COVID-19, regardless of age [4]. Furthermore, large multi-centre cohort studies have shown that a high CFS was independently associated with 30-day mortality [5]. These observations are consistent with recent cohort studies from our own population, that have shown a CFS $>3$ was independently associated with 30-day mortality in patients admitted to hospital with COVID-19 [6, 7].

However, a recent cohort study $(\mathrm{n}=1071)$ comparing the effect of frailty on 30-day mortality in COVID-19 positive and COVID-19 negative older patients ( $>65$ years), reported that frailty made only a small contribution to the hazard of dying in patients admitted with COVID19 [8]. Furthermore, independent of age, comorbidity including obesity, sarcopenia and systemic inflammation are also associated with worsened clinical outcomes [7, 9]. At present, the basis of the relationship between age, frailty and clinical outcomes is not clear. Specifically, the relationship between frailty and other recognised prognostic factors in COVID-19 is unknown. Therefore, the aim of the present study was to examine the relationship between frailty, nutritional status, CT-body composition and systemic inflammation, in patients with COVID-19.

\section{Methods}

A retrospective analysis of prospectively collected data on patients who presented to Glasgow Royal Infirmary or the Queen Elizabeth University Hospital, Glasgow, UK, between the 1st April 2020-6th July 2020 was carried out. In line with NHS policy, this study was approved by the NHS Greater Glasgow and Clyde Caldicott guardian. The study protocol (GN20AE307) was approved by the North West England-Preston research ethics committee $(20 / \mathrm{NW} / 0336)$ and registered with clinicaltrials.gov (NCT04484545).

Patients with either a positive polymerase chain reaction (PCR) test or radiological changes characteristic of COVID-19 infection, reported on chest X-ray (CXR) or $\mathrm{CT}$ thorax, by a board-certified radiologist were assessed for inclusion in the study. Exclusion criteria were as follows; patients with cross sectional scanning at the level other the third lumbar vertebra, had CT imaging out with 3 months of the diagnosis with COVID-19 or had CT imaging with significant movement artefact or missing region of interest.

Routine demographic details, clinico-pathological characteristics, frailty and nutritional assessments, as well as haematological and biochemical laboratory results were recorded. Age, sex, BMI and diagnostic modality confirming COVID-19 infection, as well as date of diagnosis, were minimal inclusion criteria. Age categories were grouped to $</ \geq 70$ years. BMI was categorised as $\leq 25 />25 \mathrm{~kg} / \mathrm{m}^{2}$. Co-morbidity data collected included a diagnosis of hypertension, heart failure, chronic obstructive pulmonary disease, type 2 diabetes mellitus, liver disease, chronic kidney disease and active cancer. Frailty was assessed using the 9-catergory Clinical Frailty Scale (CFS) [2]. Malnutrition was screened using the five-step Malnutrition Universal Screening Tool (MUST) [10]. Both frailty and MUST scores were identified from admission nursing assessments. Patients with CFS $>3$ were categorized as frail. Patients were classified as no risk $($ MUST $=0)$, or at risk of malnutrition $($ MUST $\geq 1$ ). Admission serum C-reactive protein (CRP), albumin and differential blood cell counts were categorised using local reference intervals. An autoanalyzer was used to measure serum CRP $(\mathrm{mg} / \mathrm{L})$ and albumin $(\mathrm{g} / \mathrm{L})$ concentrations (Architect; Abbot Diagnostics, Maidenhead, UK). Systemic inflammation was determined using Neutrophil/ lymphocyte ratio (NLR) [11] and the modified Glasgow Prognostic Score (mGPS) [12]. For this study, thresholds of NLR $<3,3-5$ and $>5$ were chosen. mGPS values were grouped as 0,1 and 2 .

\section{Body composition analysis}

Each CT image was individually analysed with ImageJa free to download, Java-based program developed by NIH (NIH ImageJ version 1.47, http://rsbweb.nih.gov/ ij/) shown to provide reliable measurements [13] —using our departmental standardized methodology [14, 15]. Body composition measurements derived from the CT image slice at L3 included total fat area (TFA), visceral fat area (VFA), and skeletal muscle area (SMA). Attenuation thresholds were from -190 to +30 Hounsfield units (HU) for fat and -29 to $+150 \mathrm{HU}$ for muscle. Skeletal muscle radiodensity (SMD, HU) was calculated as the mean of the measured muscle area used to calculate SMI. Subcutaneous fat area (SFA) was calculated by subtraction of the VFA from TFA. SFA and SMA measurements were then normalized by division of the patient's height in meter squared to generate subcutaneous fat index (SFI, $\mathrm{cm}^{2} / \mathrm{m}^{2}$ ) and skeletal muscle index (SMI, $\mathrm{cm}^{2} / \mathrm{m}^{2}$ ). These indices were then compared with established thresholds for body composition status [16-18].

\section{Statistical analysis}

Demographic data, clinico-pathological variables, CFS, MUST score, CT body composition measurements, mGPS and NLR were presented as categorical variables. 
Categorical variables were analysed using $\chi^{2}$ test for linear-by-linear association.

Associations between CFS and demographic data, clinicopathological variables, MUST score, CT body composition measurements, mGPS and NLR were analysed using univariate and a multivariate backward conditional approach. A $p<0.05$ was applied to inclusion at each step in the multivariate analysis.

Missing data were excluded from analysis on a variableby-variable basis. Two-tailed $p$ values $<0.05$ were considered statistically significant. Statistical analysis was performed using SPSS software version 25.0. (SPSS Inc., Chicago, IL, USA).

\section{Results}

Of the 599 patients admitted during the study period, 106 met the study inclusion criteria (See Fig. 1). The clinicopathological characteristics at presentation are shown in Table 1 . The majority of patients were aged $\geq 70$ years $(67 \%)$, male $(53 \%)$, frail (scoring $>3$ on the CFS, 72\%) and overweight (BMI > 25, 55\%). Furthermore, the majority of patients were not malnourished
(MUST $0,73 \%$ ), had $\geq 1$ co-morbidity $(87 \%)$, were sarcopenic (low SMI, 80\%) and had systemic inflammation (mGPS $>0,81 \%$, NLR > 5, 55\%).

\section{Relationship between CFS, clinico-pathological characteristics, MUST, CT-BC and systemic inflammation}

On univariate analysis, a $C F S>3$, was associated with age $(\mathrm{p}<0.001)$, hypertension $(\mathrm{p}<0.01)$, COPD $(\mathrm{p}<0.01)$, type 2 diabetes mellitus $(\mathrm{p}<0.05)$, anaemia $(\mathrm{p}<0.10)$, high SFI $(\mathrm{p}<0.10)$ and NLR $(\mathrm{p}<0.01)$. Frailty was not associated with sex $(\mathrm{p}=0.714)$, smoking history $(\mathrm{p}=0.145)$, excessive alcohol consumption history $(\mathrm{p}=0.229)$, MUST $(\mathrm{p}=0.380)$, heart failure $(p=0.211)$, liver disease $(p=0.270)$, chronic renal failure $(\mathrm{p}=0.514)$, active cancer $(\mathrm{p}=0.545), \quad$ BMI $>25$ $(\mathrm{p}=0.492)$, high VFA $(\mathrm{p}=0.965)$, low SMI $(\mathrm{p}=0.610)$, low SMD $(\mathrm{p}=0.346)$ or mGPS $(\mathrm{p}=0.278$, see Table 1$)$.

On multivariate binary logistics regression analysis, age $(\mathrm{p}<0.01)$, COPD $(\mathrm{p}<0.05)$ and NLR $(\mathrm{p}<0.05)$ remained independently associated with frailty (see Table 2).

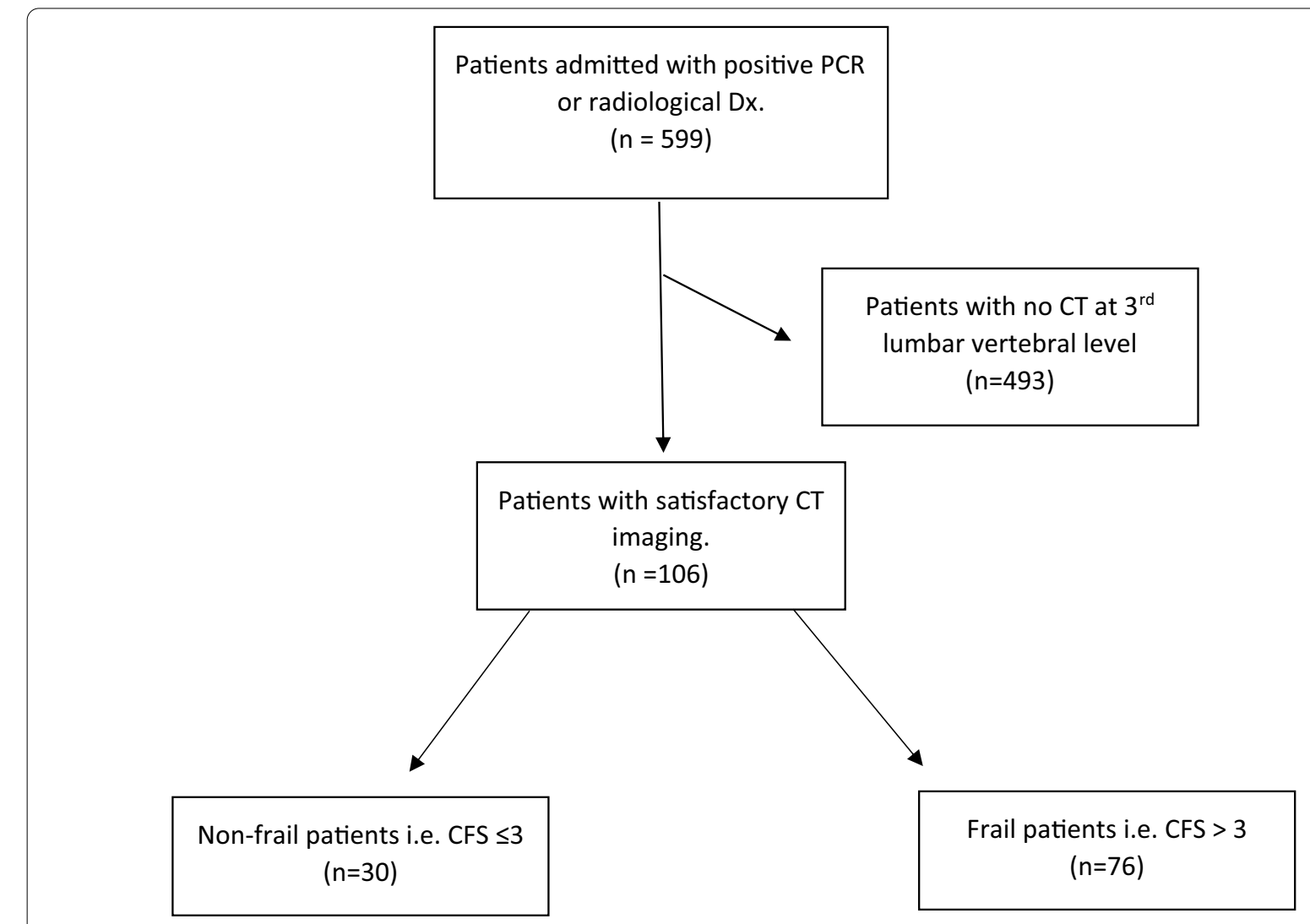

Fig. 1 Flow diagram of included patients with COVID 19 Infection and analysable CT imaging 
Table 1 The relationship between clinicopathological characteristics, MUST, CT-BC and systemic inflammation in patients with COVID19 as stratified by CFS

\begin{tabular}{|c|c|c|c|c|}
\hline Clinicopathological & All $(n=106)$ & $\begin{array}{l}\text { Non Frail }(C F S \leq 3) \\
n=30(28.3 \%)\end{array}$ & $\begin{array}{l}\text { Frail (CFS > 3) } \\
\mathrm{n}=76(71.7 \%)\end{array}$ & $P_{\text {value }}{ }^{a}$ \\
\hline Sex & & & & 0.714 \\
\hline Male & $56(52.8)$ & $15(50)$ & $41(53.9)$ & \\
\hline Female & $50(47.2)$ & $15(50)$ & $35(46.1)$ & \\
\hline Age (years) & & & & $<0.001$ \\
\hline$<70$ & $35(33.0)$ & $18(60.0)$ & $17(22.4)$ & \\
\hline$\geq 70$ & $71(67.0)$ & $12(40.0)$ & $59(77.6)$ & \\
\hline Smoking $\mathrm{Hx}$. & & & & 0.145 \\
\hline Yes & $68(64.2)$ & $16(53.3)$ & $52(68.4)$ & \\
\hline No & $38(35.8)$ & $14(47.7)$ & $24(31.6)$ & \\
\hline Alcohol excess Hx. & & & & 0.229 \\
\hline Yes & $18(17.0)$ & $3(10.0)$ & $15(19.7)$ & \\
\hline No & $88(83.0)$ & $27(90.0)$ & $61(80.3)$ & \\
\hline MUST ${ }^{b}$ & & & & 0.380 \\
\hline 0 & $53(57.6)$ & $12(50.0)$ & $41(60.3)$ & \\
\hline$\geq 1$ & $39(42.4)$ & $12(50.0)$ & $27(39.7)$ & \\
\hline Hypertension & & & & 0.006 \\
\hline Yes & $47(44.3)$ & $7(23.3)$ & $40(52.6)$ & \\
\hline No & $59(55.7)$ & $23(76.7)$ & $36(47.4)$ & \\
\hline Heart failure & & & & 0.211 \\
\hline Yes & $14(13.2)$ & $2(6.7)$ & $12(15.8)$ & \\
\hline No & $92(86.8)$ & $28(93.3)$ & $64(84.2)$ & \\
\hline COPD & & & & 0.005 \\
\hline Yes & $22(20.8)$ & $1(3.3)$ & $21(27.6)$ & \\
\hline No & $84(79.2)$ & $29(96.7)$ & $55(72.4)$ & \\
\hline $\mathrm{T} 2 \mathrm{DM}$ & & & & 0.043 \\
\hline Yes & $33(31.1)$ & $5(16.7)$ & $28(36.4)$ & \\
\hline No & $73(68.9)$ & $25(83.3)$ & $48(63.2)$ & \\
\hline Liver disease & & & & 0.270 \\
\hline Yes & $13(12.3)$ & $2(6.7)$ & $11(14.5)$ & \\
\hline No & $93(87.7)$ & $28(93.3)$ & $65(85.5)$ & \\
\hline Chronic renal failure & & & & 0.514 \\
\hline Yes & $22(20.8)$ & $5(4.7)$ & $17(22.4)$ & \\
\hline No & $84(79.2)$ & $25(83.3)$ & 59 (77.6) & \\
\hline Active cancer & & & & 0.545 \\
\hline Yes & $17(16.0)$ & $4(13.3)$ & $13(17.1)$ & \\
\hline No & $89(84.0)$ & $26(86.7)$ & $63(82.9)$ & \\
\hline Anaemia & & & & 0.065 \\
\hline Yes & $54(50.9)$ & $11(36.7)$ & $43(56.6)$ & \\
\hline No & $52(49.1)$ & $19(63.3)$ & $33(43.4)$ & \\
\hline $\mathrm{BMI}\left(\mathrm{kg} / \mathrm{m}^{2}\right)$ & & & & 0.492 \\
\hline$\leq 25$ & $48(45.3)$ & $12(40.0)$ & $36(47.4)$ & \\
\hline$>25$ & $58(54.7)$ & $18(60.0)$ & $40(52.6)$ & \\
\hline High SFI $\left(\mathrm{cm}^{2} / \mathrm{m}^{2}\right)$ & & & & 0.072 \\
\hline Yes & $79(74.5)$ & $26(86.7)$ & $53(69.7)$ & \\
\hline No & $27(25.5)$ & $4(13.3)$ & $23(30.3)$ & \\
\hline High VFA $\left(\mathrm{cm}^{2}\right)$ & & & & 0.965 \\
\hline Yes & $71(67.0)$ & $20(66.7)$ & $51(67.1)$ & \\
\hline No & $35(33.0)$ & $10(33.3)$ & 25 (32.9) & \\
\hline
\end{tabular}


Table 1 (continued)

\begin{tabular}{|c|c|c|c|c|}
\hline Clinicopathological & All $(n=106)$ & $\begin{array}{l}\text { Non Frail }(C F S \leq 3) \\
n=30(28.3 \%)\end{array}$ & $\begin{array}{l}\text { Frail (CFS > 3) } \\
\mathrm{n}=76(71.7 \%)\end{array}$ & Pvalue $^{\mathrm{a}}$ \\
\hline Low SMI $\left(\mathrm{cm}^{2} / \mathrm{m}^{2}\right)$ & & & & 0.610 \\
\hline Yes & $85(80.2)$ & $25(83.3)$ & $60(78.9)$ & \\
\hline No & $21(19.8)$ & $5(16.7)$ & $16(21.1)$ & \\
\hline Low SMD (HU) & & & & 0.346 \\
\hline Yes & $84(79.2)$ & $22(73.3)$ & $62(81.6)$ & \\
\hline No & $22(20.8)$ & $8(26.7)$ & $14(18.4)$ & \\
\hline $\mathrm{CRP}(\mathrm{mg} / \mathrm{L})$ & & & & 0.976 \\
\hline$\leq 150$ & $85(80.2)$ & $24(80.0)$ & $61(80.3)$ & \\
\hline$>150$ & $21(19.8)$ & $6(20.0)$ & $15(19.7)$ & \\
\hline Albumin (g/L) & & & & 0.716 \\
\hline$\geq 25$ & $86(81.1)$ & $25(83.3)$ & $61(80.3)$ & \\
\hline$<25$ & $20(18.9)$ & $5(16.7)$ & $15(19.7)$ & \\
\hline NLR & & & & 0.003 \\
\hline$<3$ & $25(23.6)$ & $11(36.7)$ & $14(18.4)$ & \\
\hline $3-5$ & $23(21.7)$ & $10(33.3)$ & $13(17.1)$ & \\
\hline$>5$ & $58(54.7)$ & $9(8.5)$ & $49(64.5)$ & \\
\hline mGPS & & & & 0.278 \\
\hline 0 & $20(18.9)$ & $6(20.0)$ & $14(18.4)$ & \\
\hline 1 & $13(12.3)$ & $7(23.3)$ & $6(7.9)$ & \\
\hline 2 & 73 (68.9) & $17(56.7)$ & $56(73.7)$ & \\
\hline
\end{tabular}

${ }^{a} P$ value from $x^{2}$ analysis

b 14 patients had no documented nutritional asessment on admission

Table 2 The relationship between CFS, clinicopathological characteristics, CT-BC and systemic inflammation, in patients with COVID-19 $(n=106)$

\begin{tabular}{lclll}
\hline & OR (univariate) & p-value & OR (multivariate) & p-value \\
\hline Age & $5.21(2.10-12.9)$ & 0.001 & $4.84(1.71-13.1)$ & 0.003 \\
Sex & $0.85(0.37-1.99)$ & 0.714 & - & - \\
Hypertension & $2.65(1.49-9.52)$ & 0.008 & - & 0.322 \\
COPD & $11.07(1.42-86.5)$ & 0.022 & $9.41(1.00-88.2)$ & 0.049 \\
Type 2 DM & $2.92(1.00-8.48)$ & 0.049 & - & 0.064 \\
NLR & $2.12(1.27-3.55)$ & 0.004 & $2.02(0.08-3.78)$ & 0.027 \\
\hline
\end{tabular}

COPD chronic obstructive pulmonary disease, $D M$ diabetes mellitus, $N L R$ neutrophil: lymphocyte ratio

Odds ratio, $95 \% \mathrm{Cl}$, p value

\section{Relationship between CFS, clinico-pathological characteristics, systemic inflammation and 30-day mortality}

On univariate analysis, only NLR was significantly associated with 30-day mortality (OR 2.19, 95\% CI 1.05$4.54, \mathrm{p}=0.036$, see Table 3$)$. Neither age (0.629), COPD $(\mathrm{p}=0.70)$ or frailty $(\mathrm{p}=0.298)$ were associated with 30-day mortality.
Table 3 The relationship between CFS, clinicopathological characteristics, systemic inflammation and 30-day mortality, in patients with COVID-19 $(n=106)$

\begin{tabular}{lllll}
\hline & OR (univariate) & p-value & $\begin{array}{l}\text { OR } \\
\text { (multivariate) }\end{array}$ & p-value \\
\hline Age & $1.30(0.45-3.69)$ & 0.629 & - & - \\
Frailty (CFS $>3)$ & $1.87(0.57-6.11)$ & 0.298 & - & - \\
COPD & $1.25(0.40-3.89)$ & 0.700 & - & - \\
NLR & $2.19(1.05-4.54)$ & 0.036 & - & - \\
\hline COPD chronic obstructive pulmonary disease, NLR neutrophil: lymphocyte ratio \\
Odds ratio, 95\% Cl, p value
\end{tabular}

\section{Discussion}

While the association between frailty, determined by the Clinical Frailty Scale (CFS), and clinical outcomes in patients with COVID-19 is well recognised [4], the basis of this relationship remains unclear [19]. The results of the present study found that frailty was independently associated with age, COPD and systemic inflammation. However, it was not associated with other recognised prognostic factors such as nutritional status or body composition. Therefore, it may be that the prognostic value of frailty, in patients with COVID-19, is in part dependent on chronological age, 
pre-morbid lung function and a pre-existing systemic inflammatory response.

During the first wave of the pandemic, the Clinical Frailty Scale (CFS) was utilised in the U.K and other European countries to aid decisions on treatment escalation and ceiling of care for patients admitted with COVID-19 [3, 20]. However, frailty has been considered a dynamic, somewhat reversible, process with targeted intervention $[21,22]$. As such, it is highly plausible that those admitted during the study period, who were acutely unwell with coronavirus may have present frailer than their pre-morbid baseline. Indeed, a loss skeletal muscle mass-one of many causes of functional impairment (a hallmark of frailty) [23] - has been associated with COVID-19 infection [24, 25]. However, to date there are no studies examining variations in frailty status before and after COVID-19 infection. As such, further study is required to determine if these changes are persistent, like the cognitive and functional impairments observed in patients admitted with severe sepsis [26].

Frailty is a spectrum that reflects the systemic, global burden of human aging and erosion of the patient's homeostatic reserve [27]. Although the prevalence of frailty increases with advanced age, it is not exclusive to elderly patients $[28,29]$. Indeed, Kastora and co-workers found that when adjusted for age, frailty as defined by CFS, was independently associated with increased mortality in patients with COVID-19. However, it is highly likely that those who are elderly would be frail, and vice versa. This is in keeping with the observations of the present study that found frailty remained independently associated with age on multivariate binary logistics regression analysis. Therefore, further studies with a range of age groups will be required to tease out the prognostic value of frailty in patients with COVID-19.

In the present study, frail patients $(\mathrm{CFS}>3)$ admitted with COVID-19 were significantly more likely to be hypertensive, non-insulin dependent diabetics and have COPD compared to those who were not frail (See Table 1). This observation is consistent with recent work by Hanlon et al. who found that in a biobank of 493, 737 patients, that frailty was associated with comorbidity [30]. Therefore, while the current literature suggests that frailty has prognostic value in patients with COVID-19 [4], it is of interest that diabetes mellitus [31], ischaemic heart disease [32] and COPD [33] have also shown an association with worsened outcomes. As such, it remains unclear whether frailty has independent prognostic value in patients with COVID-19 or is simply reflective of other prognostic domains such as co-morbid disease. Indeed, the impact co-morbidity has on the prognostic value of frailty in those with COVID-19 is exemplified in the work of
Owen et al., who found that when adjusted for co-morbidity, frailty did not significantly impact mortality in elderly patients hospitalised with COVID-19 infection [8]. As such, further study is required to delineate if frailty remains prognostic in co-morbid patients with COVID-19 or is simply reflective of other prognostic domains.

While the basis of the relationship between frailty and clinical outcomes remains unclear, a recent review by Hussien et al. hypothesised that frail patients have a preexisting immuno-pathological base, that puts them at a higher risk of mortality if they contract COVID-19 [19]. Indeed, a chronic inflammatory response and immunosenescence is recognised with advanced age $[34,35]$. In the present study, systemic inflammation, as measured by NLR, was associated with frailty and 30-day mortality. The present observations are in keeping with recent cohort studies that found an elevated NLR was associated with negative outcomes in patients with COVID-19 $[36,37]$. Therefore, it may be speculated that the prognostic value and treatment of the systemic inflammatory response will be greatest in older, frail patients with COVID-19. However, few studies to date have examined the relationship between frailty and systemic inflammation [35]. Therefore, it remains unclear if relationship between frailty and systemic inflammation in patients with COVID-19 is independent of age.

There are a number of limitations of this present study. Firstly, the small sample size and limited observations having the potential for sparse data bias. Secondly, CT imaging of the abdomen at the level of the third lumbar vertebra is not routine practice in patients admitted with COVID-19. These patients were identified from admission with a positive PCR test and their medical records retrospectively screened for CT-imaging facilitating body composition analysis within 3 months of their positive PCR date, in keeping with standard practice of our unit. As such this may introduce selection bias into the cohort. Nevertheless, the present study has the largest cohort to date exploring the relationship between frailty, malnutrition, CT-body composition measurements and systemic inflammation in patients with COVID-19 infection, providing a novel insight into the relationship of frailty and other recognised prognostic factors. Lastly, the Clinical Frailty Scale (CFS) is a subjective assessment and therefore subject to observer bias. However, high inter-rater agreement of frailty scoring in patients with critical illness, across a range of healthcare professionals, has been reported [38]. Therefore, it is plausible that the prevalence of frailty in the present study and the associations observed, are representative of patients admitted with COVID-19. Nevertheless, it would be of interest to compare frailty prevalence and associations across multiple 
screening measures, also shown to have prognostic value, in patients admitted with COVID-19 [39].

In summary, frailty was independently associated with age, co-morbidity, and systemic inflammation. However, the basis of the relationship between frailty and clinical outcomes in COVID-19 requires further study.

\section{Abbreviations}

BMI: Body mass index; CFS: Canadian Study of Health and Aging-Clinical Frailty Scale; COPD: Chronic obstructive pulmonary disease; COVID-19: Coronavirus disease; CRP: C-reactive protein; CT-BC: CT-body composition; CXR: Chest radiograph; DM: Diabetes mellitus; mGPS: Modified Glasgow Prognostic Score; NLR: Neutrophil: Iymphocyte ratio; PCR: Polymerase chain reaction; SFI: Subcutaneous fat index $\left(\mathrm{cm}^{2} / \mathrm{m}^{2}\right)$; SMA: Skeltal muscle area $\left(\mathrm{cm}^{2}\right)$; SMD: Skeletal muscle radiodensity (HU); SMI: Skeletal muscle index $\left(\mathrm{cm}^{2} / \mathrm{m}^{2}\right)$; TFA: Total fat area $\left(\mathrm{cm}^{2}\right)$; VFA: Visceral fat area $\left(\mathrm{cm}^{2}\right)$; WHO: World Health Organization.

\section{Acknowledgements}

Nil to add.

\section{Authors' contributions}

JM wrote the paper and analysed the data. RDD aided in conceptualization, writing the paper and statistical analysis. YA, OK, PM and CR aided in data collection and analysis. BJL, DCM and DM aided in conceptualization, reviewing, and writing of the paper. DCM and DM had primary responsibility for final content. All authors read and approved the final manuscript.

\section{Funding}

There is no funding to declare.

\section{Availability of data and materials}

Data will be made available following request to the senior authors.

\section{Declarations}

\section{Ethics approval and consent to participate}

The study protocol (GN20AE307) was approved by the North West England-Preston research ethics committee (20/NW/0336) and registered with clinicaltrials.gov (NCT04484545).

\section{Consent for publication}

All authors have given their consent for publication.

\section{Competing interests}

There is no conflicts of interest to declare.

\section{Author details}

${ }^{1}$ Academic Unit of Surgery, University of Glasgow, Level 2, New Lister Building, Glasgow G31 2ER, UK. ²Emergency Department, Glasgow Royal Infirmary, Glasgow G4 OSF, UK. ${ }^{3}$ Institute of Genetics and Molecular Medicine, University of Edinburgh, Edinburgh EH4 2XU, UK.

Received: 4 August 2021 Accepted: 8 February 2022

Published online: 21 February 2022

\section{References}

1. World Health Organization. WHO Director-General's opening remarks at the media briefing on COVID-19-12 October 2020. 2020. https://www. who.int/director-general/speeches/detail/who-director-general-s-openi ng-remarks-at-the-media-briefing-on-covid-19---12-october-2020. Accessed 3 Feb 2021.

2. Rockwood K, Song X, MacKnight C, Bergman H, Hogan DB, McDowell I, et al. A global clinical measure of fitness and frailty in elderly people. CMAJ. 2005;173(5):489-95.
3. Excellence NIfHaC. National Institute for Health and Care Excellence: Clinical Guidelines. COVID-19 rapid guideline: managing suspected or confirmed pneumonia in adults in the community. London: National Institute for Health and Care Excellence (UK) Copyright @ NICE 2020. 2020.

4. Kastora S, Kounidas G, Perrott S, Carter B, Hewitt J, Myint PK. Clinical frailty scale as a point of care prognostic indicator of mortality in COVID-19: a systematic review and meta-analysis. EClinicalMedicine. 2021;36: 100896.

5. Collaborative GMR. Age and frailty are independently associated with increased COVID-19 mortality and increased care needs in survivors: results of an international multi-centre study. Age Ageing 2021;50(3):617-30.

6. Maguire D, Richards C, Woods M, Dolan R, Wilson Veitch J, Sim WMJ, et al. The systemic inflammatory response and clinicopathological characteristics in patients admitted to hospital with COVID-19 infection: comparison of 2 consecutive cohorts. PLoS ONE. 2021;16(5): e0251924.

7. Maguire D, Woods M, Richards C, Dolan R, Veitch JW, Sim WMJ, et al. Prognostic factors in patients admitted to an urban teaching hospital with COVID-19 infection. J TransI Med. 2020;18(1):354.

8. Owen RK, Conroy SP, Taub N, Jones W, Bryden D, Pareek M, et al. Comparing associations between frailty and mortality in hospitalised older adults with or without COVID-19 infection: a retrospective observational study using electronic health records. Age Ageing. 2021;50(2):307-16.

9. McGovern J, Dolan R, Richards C, Laird BJ, McMillan DC, Maguire D. Relation between body composition, systemic inflammatory response, and clinical outcomes in patients admitted to an urban teaching hospital with COVID-19. J Nutr. 2021;151(8):2236-44.

10. Nutrition BAfPaE. Introducing 'MUST'. 2016. https://www.bapen.org.uk/ screening-and-must/must/introducing-must. Accessed 24 May 2021.

11. Zahorec R. Ratio of neutrophil to lymphocyte counts_-rapid and simple parameter of systemic inflammation and stress in critically ill. Bratisl Lek Listy. 2001;102(1):5-14.

12. McMillan DC, Crozier JE, Canna K, Angerson WJ, McArdle CS. Evaluation of an inflammation-based prognostic score (GPS) in patients undergoing resection for colon and rectal cancer. Int J Colorectal Dis. 2007;22(8):881-6.

13. Feliciano EMC, Kroenke CH, Meyerhardt JA, Prado CM, Bradshaw PT, Kwan $\mathrm{ML}$, et al. Association of systemic inflammation and sarcopenia with survival in nonmetastatic colorectal cancer: results from the C SCANS study. JAMA Oncol. 2017:3(12): e172319.

14. Abbass T, Dolan RD, Laird BJ, McMillan DC. The relationship between imaging-based body composition analysis and the systemic inflammatory response in patients with cancer: a systematic review. Cancers. 2019;11(9):1304.

15. McSorley ST, Black DH, Horgan PG, McMillan DC. The relationship between tumour stage, systemic inflammation, body composition and survival in patients with colorectal cancer. Clin Nutr. 2018;37(4):1279-85.

16. Martin L, Birdsell L, Macdonald N, Reiman T, Clandinin MT, McCargar LJ, et al. Cancer cachexia in the age of obesity: skeletal muscle depletion is a powerful prognostic factor, independent of body mass index. I Clin Oncol. 2013;31(12):1539-47.

17. Ebadi M, Martin L, Ghosh S, Field CJ, Lehner R, Baracos VE, et al. Subcutaneous adiposity is an independent predictor of mortality in cancer patients. Br J Cancer. 2017;117(1):148-55.

18. Doyle SL, Bennett AM, Donohoe CL, Mongan AM, Howard JM, Lithander $\mathrm{FE}$, et al. Establishing computed tomography-defined visceral fat area thresholds for use in obesity-related cancer research. Nutr Res. 2013;33(3):171-9.

19. Hussien H, Nastasa A, Apetrii M, Nistor I, Petrovic M, Covic A. Different aspects of frailty and COVID-19: points to consider in the current pandemic and future ones. BMC Geriatr. 2021;21(1):389.

20. Blomaard LC, van der Linden CMJ, van der Bol JM, Jansen SWM, PolinderBos HA, Willems HC, et al. Frailty is associated with in-hospital mortality in older hospitalised COVID-19 patients in the Netherlands: the COVID-OLD study. Age Ageing. 2021;50(3):631-40.

21. Puts MTE, Toubasi S, Andrew MK, Ashe MC, Ploeg J, Atkinson E, et al. Interventions to prevent or reduce the level of frailty in community-dwelling older adults: a scoping review of the literature and international policies. Age Ageing. 2017;46(3):383-92.

22. Campbell AJ, Buchner DM. Unstable disability and the fluctuations of frailty. Age Ageing. 1997;26(4):315-8. 
23. Cooper C, Dere W, Evans W, Kanis JA, Rizzoli R, Sayer AA, et al. Frailty and sarcopenia: definitions and outcome parameters. Osteoporos Int. 2012;23(7):1839-48.

24. Morley JE, Kalantar-Zadeh K, Anker SD. COVID-19: a major cause of cachexia and sarcopenia? J Cachexia Sarcopenia Muscle. 2020;11(4):863-5.

25. Barazzoni R, Bischoff SC, Breda J, Wickramasinghe K, Krznaric Z, Nitzan $D$, et al. ESPEN expert statements and practical guidance for nutritional management of individuals with SARS-CoV-2 infection. Clin Nutr. 2020;39(6):1631-8.

26. Iwashyna TJ, Ely EW, Smith DM, Langa KM. Long-term cognitive impairment and functional disability among survivors of severe sepsis. JAMA. 2010;304(16):1787-94.

27. Clegg A, Young J, lliffe S, Rikkert MO, Rockwood K. Frailty in elderly people. Lancet. 2013;381(9868):752-62.

28. Rockwood K, Song X, Mitnitski A. Changes in relative fitness and frailty across the adult lifespan: evidence from the Canadian national population health survey. CMAJ. 2011;183(8):E487-94.

29. Mitnitski A, Rockwood K. The rate of aging: the rate of deficit accumulation does not change over the adult life span. Biogerontology. 2016;17(1):199-204

30. Hanlon P, Nicholl BI, Jani BD, Lee D, McQueenie R, Mair FS. Frailty and pre-frailty in middle-aged and older adults and its association with multimorbidity and mortality: a prospective analysis of 493737 UK Biobank participants. Lancet Public Health. 2018;3(7):e323-32.

31. Gregg EW, Sophiea MK, Weldegiorgis M. Diabetes and COVID-19: population impact 18 months into the pandemic. Diabetes Care. 2021;44(9):1916-23.

32. Peterson E, Lo KB, DeJoy R, Salacup G, Pelayo J, Bhargav R, et al. The relationship between coronary artery disease and clinical outcomes in COVID-19: a single-center retrospective analysis. Coron Artery Dis. 2021;32(5):367-71.

33. Reyes FM, Hache-Marliere M, Karamanis D, Berto CG, Estrada R, Langston $M$, et al. Assessment of the association of COPD and asthma with inhospital mortality in patients with COVID-19. A systematic review, metaanalysis, and meta-regression analysis. J Clin Med. 2021;10(10):2087.

34. Franceschi C, Bonafè M, Valensin S, Olivieri F, De Luca M, Ottaviani E, et al. Inflamm-aging: an evolutionary perspective on immunosenescence. Ann NY Acad Sci. 2000;908(1):244-54. https://doi.org/10.1111/j.1749-6632. 2000.tb06651.x.

35. Zanetti M, Marzaro G, De Colle P, Toigo G, Bianchini D, Nastri M, et al. Predictors of short- and long-term mortality among acutely admitted older patients: role of inflammation and frailty. Aging Clin Exp Res. 2021. https://doi.org/10.1007/s40520-021-01926-8

36. Yang AP, Liu JP, Tao WQ, Li HM. The diagnostic and predictive role of NLR, d-NLR and PLR in COVID-19 patients. Int Immunopharmacol. 2020;84: 106504.

37. Liu J, Liu Y, Xiang P, Pu L, Xiong H, Li C, et al. Neutrophil-to-lymphocyte ratio predicts critical illness patients with 2019 coronavirus disease in the early stage. J Transl Med. 2020;18(1):206.

38. Flaatten H, Guidet B, Andersen FH, Artigas A, Cecconi M, Boumendil A et al. Reliability of the clinical frailty scale in very elderly ICU patients: a prospective European study. Ann Intensive Care. 2021;11(1):22.

39. Petermann-Rocha F, Hanlon P, Gray SR, Welsh P, Gill JMR, Foster H, et al. Comparison of two different frailty measurements and risk of hospitalisation or death from COVID-19: findings from UK Biobank. BMC Med. 2020;18(1):355.

\section{Publisher's Note}

Springer Nature remains neutral with regard to jurisdictional claims in published maps and institutional affiliations. 